\section{Liebermann-Burchard Reaction}

THE Liebermann-Burchard reaction ${ }^{1}$ is extensively used for the characterization of polynuclear compounds (steroids, polyterpenoids, etc.). Applying this reaction to some of these compounds and simpler ones, according to the conditions described by Nath, Chakravorty and Chowdhury ${ }^{2}$ with enough chloroform to give a homogeneous medium, colloidal solutions are obtained. With cholesterol, $\beta$-amyrenol, abietic acid, limonene, cyclohexanone and linalool, the solutions are strongly coloured and show a strong Tyndall effect and Brownian movement by the ultramicroscope.

Adding a large excess of ether (dry over sodium), a precipitate is obtained, which is in each case very soluble in water. affording an acid-base conjugated pair. The colours are shown in the accompanying table.

\begin{tabular}{|c|c|c|c|c|}
\hline \multirow{2}{*}{ Substance } & \multirow{2}{*}{$\begin{array}{l}\text { Chloroform } \\
\text { solution }\end{array}$} & \multirow{2}{*}{ Precipitate } & \multicolumn{2}{|c|}{ Aqueous solution } \\
\hline & & & acid & base \\
\hline $\begin{array}{l}\beta \text {-Amyrenol } \\
\text { Cholesterol }\end{array}$ & pink-violet & $\begin{array}{l}\text { blue } \\
\text { green }\end{array}$ & $\begin{array}{l}\text { violet } \\
\text { green }\end{array}$ & $\begin{array}{l}\text { yellow } \\
\text { orange }\end{array}$ \\
\hline Abietic acid & violet-blue- & grey-green & green & orange \\
\hline Limonene & dark-red & black & brown & yellow \\
\hline Cyclohexanone & $\begin{array}{c}\text { dark-yellow- } \\
\text { red-dark }\end{array}$ & violet & violet & yellow \\
\hline Linalool & dark-red & black-brown & green-brown & orange \\
\hline
\end{tabular}

The existence of only one acid-base dye was proved chromatographically, passing the aqueous solution through a column with alumina, in acid medium, and in basic medium. The aqueous solutions of the acids and the conjugated base are also colloidal.

and the conjugated base are also colloidal.
When the acids are allowed to stand in contact with the air, they When the acids are allowed to stand in contact with the air, they
give yellow products soluble in water; the rate of this transformation give yellow products soluble in water ; the rate of this transformation is greater in presence of light. The yellow products become deeper
yellow by addition of bases. Full details will be published at a later yellow

We would like to thank Prof. Ruy Couceiro da Costa, director of the Chemical Department, and Prof. A. J. A. de Gouveis, for their the Chemical Departm
interest in this work.

Laboratório Químico da Faculdade

F. Pinto Coniho

de Ciências da Universidade de Coimbra

Centro de Estudos de Quimica.

$$
\text { April } 16 .
$$

${ }^{1}$ Liebermann, C., Ber., 18, 1804 (1885). Burchard, O., Diss. Rostock

${ }^{2}$ Nath, M. C., Chakravorty, M. K., and Chowdhury, S. R., Nature, 157, 103 (1946).

\section{Effect of Sulphadiazine on the Metabolism of Aneurin in Animals}

IT is well established that some of the toxic effects of sulphonamides on animals fed purifled diets are caused by inhibition of bacterial synthesis of some B vitamins in the intestine, with consequent development of defleiency states. Few attempts have been made, however, to determine if the sulphonamides have a more fundamental effect on the metabolism of the $\mathrm{B}$ vitamins in the animal body. The purpose of the present communication is to make a preliminary report on experiments which suggest that sulphadiazin

A healthy male, aged 27 years and weighing $82.5 \mathrm{kgm}$, was fed constant diet for 19 days. The diet provide $82 . \mathrm{kgm}$., was fed all nutrients content of the diet was (by analysis) 0.57 . The aneurin conter 17 . the daily the daily dosage (one quarter of which was taken four times a day is shown in the graph. analyed for aning ingestion of the of tho bod an in the graph.

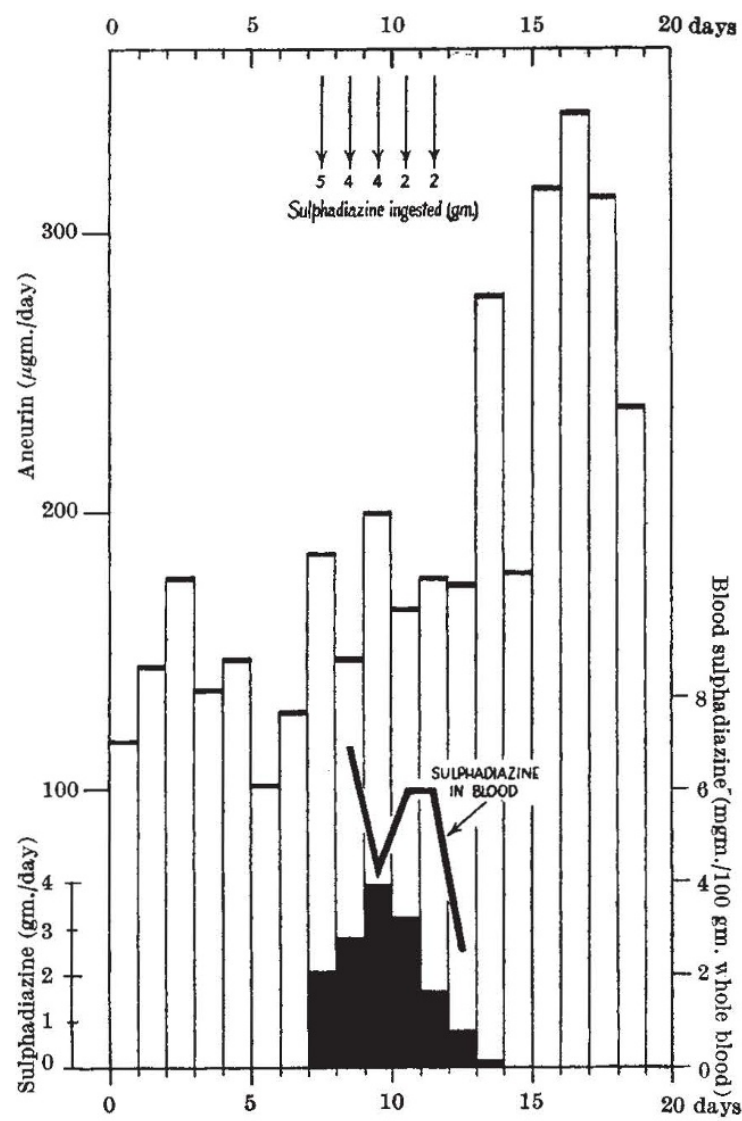

EFFEOT OF INGESTION OF SULPHADIAZINE ON THE URINARY EXCRETION OF ANEURIN

Open columns : urinary excretion of aneurin; blocked columns : urinary excretion of sulphadiazine;
of blood.

The mean daily urinary excretions of aneurin before and during ingestion of sulphadiazine were 136 and $175 \mu \mathrm{gm}$. respectively; the increase during ingestion $(39 \mu \mathrm{gm} .=27$ per cent) was statistically signiflcant $(P<0.02)$. After ingestion of the drug had ceased th excretion of aneurin continued to increase, reaching a peak (344 , the five days later at which time sulphadiazine was no longer detectable in the urine. The aneurin excretion declined over the next few days, but the experiment was discontinued before normal levels of ex days, were restored.

Further studies of the effect of sulphadiazine on aneurin meto bolism were made by measuring the aneurin content of the livera rats fed a diet suboptimal in aneurin. The diet was also mader of rats in ribulu to enable a study of the effect made sub optimalin ribofla metabolism. The diet consisted of casein $18 \mathrm{gm}$.' sucrose $73 \mathrm{gm}$. salt mixture 4 gm., pea-nut oil $2.5 \mathrm{gm}$., cod liver oil $2 \mathrm{gm}$., and wheat germ oil $0.35 \mathrm{gm}$. The following synthetic vitamins were provided per $100 \mathrm{gm}$. diet : nicotinic acid $5 \mathrm{mgm}$., pyridoxine $0.5 \mathrm{mgm}$., inosito $16 \mathrm{mgm}$., calcium pantothenate $4 \mathrm{mgm}$. and choline $0.2 \mathrm{gm}$. In 8ddition, $6.9 \mu \mathrm{gm}$. aneurin and $10.3 \mu \mathrm{gm}$. riboflavin a day were given by pipette to each rat. Folic acid and biotin deflciency develop in the rat when a sulpha drug is fed with such a diet, owing to inhibition fore necessary to have two control groups, one fed the basal diet

ANALYSES-MEANS OF GROUPS AND SIGNIFTCANCE OF DIFFRRENOES

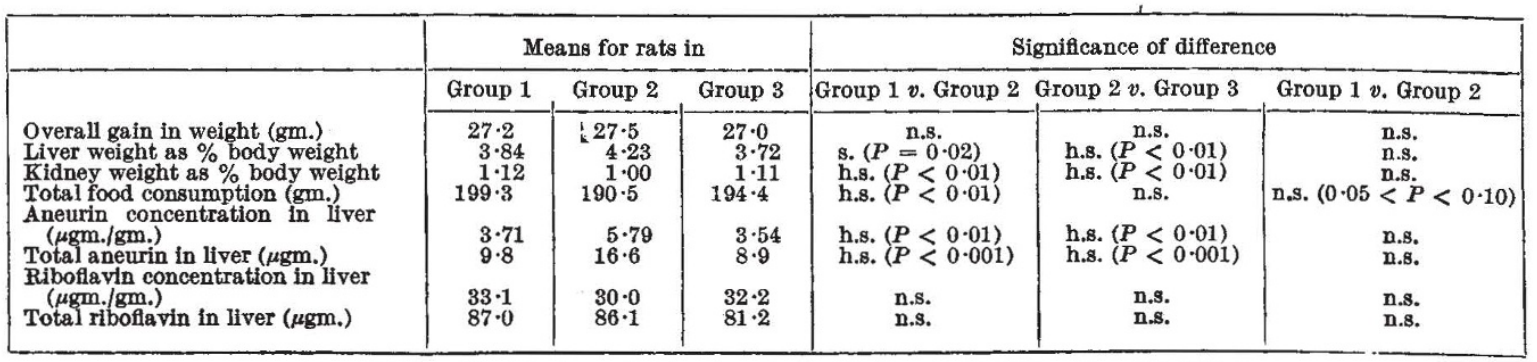

n.s. $=$ Not significant $; \quad$ s. $=$ significant $;$ h.s. $=$ highly signifleant $; \quad P=$ probability . 